\title{
Colour terms in Indonesian sign language varieties: A preliminary study.
}

\author{
Nick Palfreyman
}

\section{Introduction}

As more research is conducted on sign language variation, it is becoming clear that the semantic domain of colour terms often exhibits lexical variation cross-linguistically. Recent studies report that Italian Sign Language has at least eight lexical variants for 'brown' and 11 for 'blue' (SilverSwartz 2012), while British Sign Language has no fewer than 14 lexical variants for 'grey' and an astonishing 22 lexical variants for 'purple' (Stamp 2013:238). Other sign languages that are reported to exhibit variation in this domain include Australian Sign Language (Johnston 1998), German Sign Language (Eichmann and Rosenstock 2014) and Japanese Sign Language. ${ }^{1}$

This chapter is concerned with Indonesian sign language varieties, which also exhibit phonological and lexical variation in the semantic domain of colour terms. The findings presented here are based primarily on data collected from six sign language users in Solo (Central Java) and six in Makassar (Sulawesi), using the elicitation activities for colour terms described in the Introduction. Details concerning Indonesian sign language varieties, the sign community, deaf schools, and the method used to collect and analyse data are presented in sections 1.1 and 1.2.

In the data, participants produce 39 mono-lexemic variants for eleven colour terms. These include 29 lexical variants, which are further categorised according to whether or not they are initialised. Initialisation is a phenomenon common to many - though not all - sign languages, whereby signs include the handshape of the initial letter of the word in a corresponding written language (see section 3). This is an example of the impact that language contact has had on the expression of colour terms. Language contact can also, perhaps, explain changes that have taken place in the inventory of colour terms (section 4).

Within the semantic domain of colour terms, there are multiple sets of lexical variants from which signers may choose in both the Makassar and 
Solo varieties. The question of how signers cope with this variation is considered further in section 5, alongside examples of intra-individual variation. Sets of lexical variants ('lexical sets'), and the factors that can explain this phenomenon, are discussed in section 6.

Findings presented here are based on data collected from the sign language varieties of Solo and Makassar. References are made to other urban varieties as appropriate, including varieties on the islands of Java (Jakarta, Surabaya, Yogyakarta), Borneo (Banjarmasin) and Sulawesi (Manado), as illustrated in Map 1.

The overview of colour term variants in this chapter is necessarily preliminary, in that the analysis is confined to what can be deduced from the variants that 12 informants produced during elicitation activities. Additionally, just two urban sign language varieties are included, although colour terms were also elicited from two signers in Jakarta in order to contextualise the main findings. Further, a Solonese informant who now works in the city of Surabaya was able to give examples of what he perceives as typical Surabayan variants; this is particularly interesting because of anecdotal reports that the Surabaya variety has borrowed heavily from American Sign Language (ASL) in the domain of colour terms. Contact with Surabayan variants has led to the adoption of some, but not all of these variants by Solonese signers (4.2).

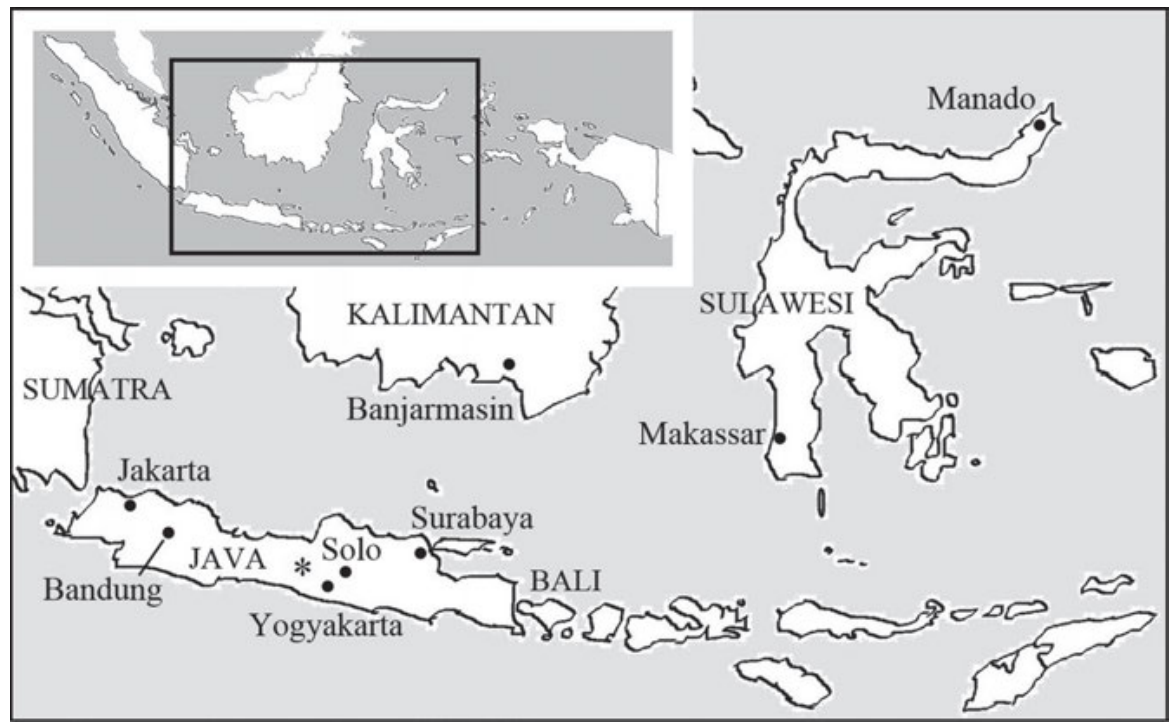

Map 1. A map of Indonesia with urban centres mentioned in this chapter. 
As with other sign languages, examples can be found of variation between urban centres in Indonesia, but variation within each urban centre is often considerable. Some contributory factors are described in section 1.1, where the history of the urban sign community is sketched. The method used to collect and analyse data is described in section 1.2, and colour terms are then detailed in the subsequent sections.

\subsection{A brief history of the sign community in Indonesia}

Sign language varieties in Indonesia are severely under-documented. A notable exception to this is Kata Kolok, a 'village sign language' variety used in the Balinese village of Bengkala. Kata Kolok is relatively well-documented (e.g. Marsaja 2008, de Vos 2012) and is thought to have a time depth of around five generations (de Vos 2012:47) but not known to be related to any other varieties. For urban sign language varieties, several lexicographical studies have recently been conducted for varieties in Jakarta (Wijaya \& Satryawan 2013) and Yogyakarta (Sukmara 2014, Bharoto 2013a), alongside preliminary studies of classifier constructions (Bharoto 2013b) and sign names (Chu and Wijaya 2013). Isma (2012) presents a basic comparison of the Jakarta and Yogyakarta varieties focusing on 'core' lexicon and word order, and Suwiryo (2013) compares mouthings in the same varieties. Aside from Palfreyman $(2013,2015)$, no studies have included urban sign language varieties outside of Java.

The number of sign language users in Indonesia has not been reported, and is not easy to establish. Using figures provided by the Ministry for Social Affairs and the Central Body for Statistics, Gerkatin (the Indonesian Association for the Welfare of the Deaf) believes that the number is likely to fall somewhere between 600,000 and three million, although it is not likely that all of these deaf people communicate using sign language. More recently, data from the 2010 census have been made available, which suggest that the number of severely or profoundly deaf Indonesians is at least half a million, and almost certainly much higher (Palfreyman 2015).

Given the dearth of linguistic and sociolinguistic research on sign language varieties in Indonesia, it is too early to say whether it is more appropriate to refer to a single 'Indonesian Sign Language', or to several different sign languages, either on linguistic or socio-political grounds. With that in mind, I refer here to sign language varieties rather than to ' $\mathrm{X}$ Sign Language'. The shared experiences of deaf people in different urban centres, and the language contact between them (described in 1.1.1-1.1.3) are good 
reasons for referring to the existence of an Indonesian sign community that comprises a network of sub-communities of sign language users in most, if not all urban centres across Indonesia. However, while a minority of deaf people have travelled extensively within Indonesia, the experiences of most urban sign language users are very much local, and the majority of deaf people are not well-travelled.

\subsubsection{Deaf schools}

The history of deaf education is often very important when seeking to detect and explain variation in sign languages. A good example of this is the existence in Britain of several schools for deaf children, which is key to explaining historic variation in British Sign Language (Stamp 2013). Deaf schools, as centres of language transmission, are often crucial to the persistence of sign language varieties (Quinn 2010), and the existence of several schools is well known to produce lexical differences. This is what happened in Dublin, where the segregation of deaf children at Catholic schools led to considerable gender variation in Irish Sign Language during the twentieth century (Le Master and Dwyer 1991, Leeson and Grehan 2004).

In the archipelago that is now known as Indonesia, the foundation and existence of several deaf schools can help to explain similarities and the differences both between and within different sign language varieties. The first Indonesian school for deaf children was founded in 1930 in Bandung by a Dutch expatriate. In 1938, a second school was founded in Wonosobo, Central Java (marked by an asterisk on Map 1) and staffed by Catholic sisters, the Daughters of Mary and Joseph. Both of these schools closed for a period following the Japanese occupation in 1942, but re-opened in the 1950s, and a third school (Don Bosco) was set up, also in Wonosobo, by Catholic brothers. All three had links with deaf schools in the Netherlands, where oral teaching methods were favoured at the time, which is how oralism was introduced to Indonesia. Interviews with nuns who taught in Wonosobo show that the use of sign language was forbidden (see Palfreyman 2015), but despite this it seems that sign language was often used socially by deaf children.

All of these schools were privately-run, and attracted deaf pupils not only from the surrounding area but from further afield, and increasingly from other Indonesian islands. For example, between 1970 and 1980, 49 out of 342 pupils (14.3\%) who registered at the Don Bosco school in Wonosobo 
came from outside of Java, including six from Papua, some 3,000 km away. Most deaf children seem to have returned to their region of origin once they had finished school.

Elsewhere in Indonesia, a school for deaf children was founded in Makassar in 1958 by a woman who had trained in Bandung. Other schools for deaf children were founded in Solo in 1961, and Medan, Sumatra, in 1965. Interestingly, the first deaf school in the Indonesian capital, Jakarta, was not established until 1970. Another school opened in Indonesia's second largest city, Surabaya, in 1977. In the 1980s and 1990s, the Indonesian government started to establish state schools for deaf children. There are now government-run schools for deaf children in most of Indonesia's 34 provinces, and some of these provinces have several such schools.

\subsubsection{Contact between sub-communities of sign language users}

Besides schools, deaf organisation has been one of the main reasons for language contact between sub-communities of sign language users in Indonesia. Organisations of deaf people developed slowly from the 1950s onwards, emerging first in Java as alumni associations. The first of these were established in Bandung $(1958,1960)$, and others appeared in Jakarta (1965), Yogyakarta (1974, 1980), Semarang (1976) and Surabaya (1979).

Through this network of smaller organisations, the national Indonesian Association for the Welfare of the Deaf ('Gerkatin') emerged in 1981. To date, Gerkatin has held eight national congresses. The earliest of these did not include representation from many provinces without Java. However, two of the most recent three congresses have taken place in Bali (2002) and Makassar (2006), and as of 2013, regional bodies of Gerkatin exist in some shape or form in all but seven of Indonesia's 34 provinces.

Language contact between different sub-communities of sign language users has also taken place at regional and national gatherings for sports meetings, cultural competitions and scouts jamborees. These events have taken place intermittently since the 1960 s, organised by bodies such as government departments, deaf sports organisations, and Disabled People's Organisations. Another factor that has led to language contact between sub-communities within Indonesia is internal migration, where sign language users have moved in order to find employment, to get married, or to escape from conflict (see Palfreyman 2015 for examples of this). 


\subsubsection{The introduction of manually coded systems}

In the early 1980s, signs from American Sign Language (ASL) and the philosophy behind Signed Exact English (SEE) were introduced to schools in Jakarta and Surabaya in the form of manually coded language systems. These systems seek to represent the grammar of spoken language on the hands, and in theory hearing teachers and parents can speak and sign simultaneously, although the systems vary in the amount of grammatical information that is conveyed. By the 1990s, the Indonesian government had endorsed the version that had developed in the schools of Jakarta and Surabaya, which came to be acronymised as SIBI (the Indonesian Sign System).

SIBI aims to represent the national spoken language of Indonesia Bahasa Indonesia - morpheme by morpheme, and several editions of the SIBI dictionary have been published and disseminated by the Indonesian government since 1994 (see Palfreyman 2015 for a critique of SIBI). ${ }^{2}$ The manual alphabet that is promoted by SIBI, and which forms the handshapes for its many initialised signs, is identical to that of ASL, with the exception of the sign that represents the letter ' $T$ '. SIBI is not used at all in some schools (Branson and Miller 2004: 18), but others place a strong emphasis on its acquisition by deaf children.

Contact with SIBI in school has undoubtedly had an effect on the sign language varieties used in the wider sign community. In many urban centres, the one-handed alphabet is readily used as well as, or instead of, the twohanded alphabet, especially by younger signers. SIBI has had more influence on the sign language varieties of some sub-communities than others, even on the same island. For example, SIBI seems to have influenced the forms used in Manado more than those in Makassar. The existence of an older generation who have had no exposure to SIBI, along with the patchy implementation of SIBI and the selective use of SIBI signs by younger signers, all contribute to the variation described in this chapter.

\subsection{Method}

\subsubsection{Data collection and analysis}

The descriptions in this chapter are based on linguistic data obtained through elicitation and from spontaneous conversation. Three hours of natural conversational data collected from Solo (in 2010) and Makassar (2011) have been used to create an organised corpus (see Palfreyman 2015 for details). Searches of 
this corpus show how terms from a target domain are expressed in the Solo and Makassar varieties, including examples of real constituent order and variation.

Spontaneous conversation does not usually generate many examples of colour terms, most of which do not occur in the corpus at all. Even in large corpora, complete sets are not always available, and so corpus methods have been supplemented by elicitation, observation, and introspection from my research assistants Muhammad Isnaini, Jayeng Pranoto and Oktaviani Wulansari. Elicited data have been collected in Solo and Makassar in 2011 using the games described in Sagara \& Zeshan, this volume.

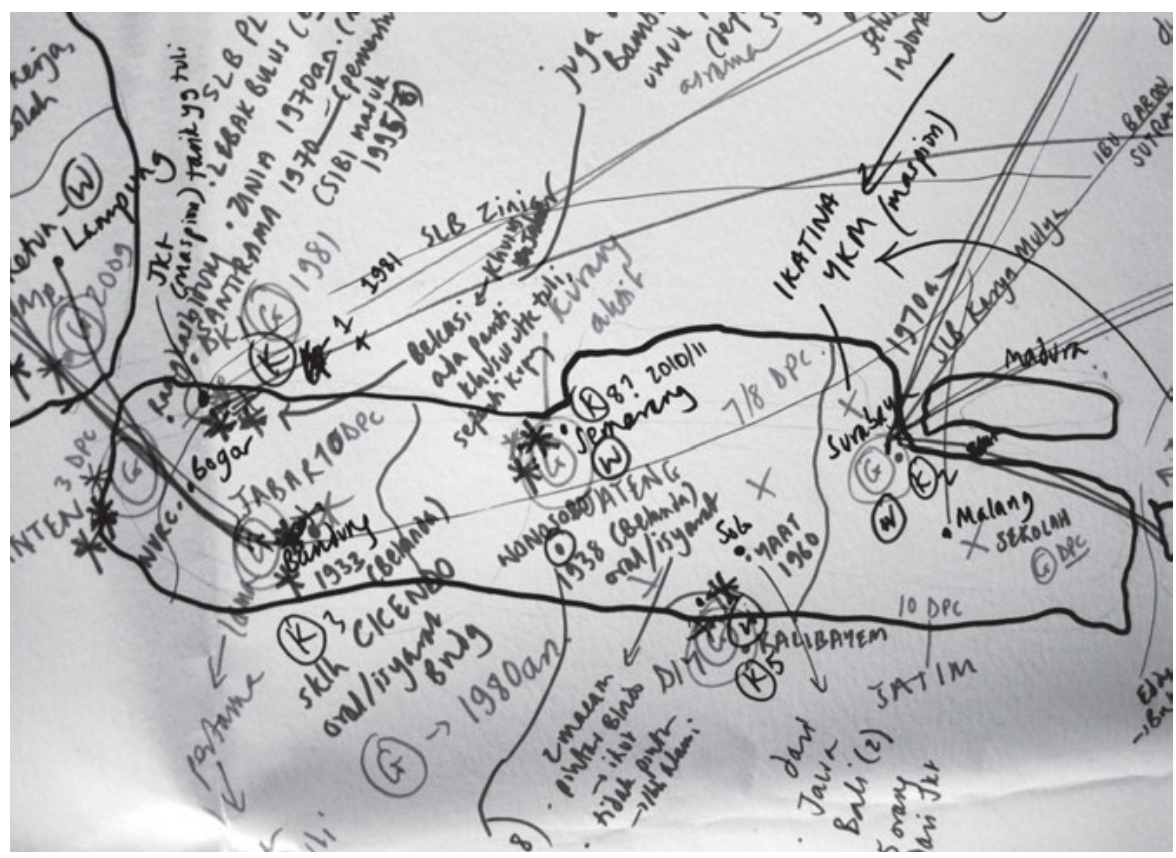

Figure 1. A section of the sociolinguistic map (December 2010).

Examples from other urban centres were noted during preliminary field visits in 2010 (Banjarmasin) and 2011 (Jakarta and Manado). Several sign language users in Solo have previously worked in Surabaya, and some have a good knowledge of variants that are particular to that city. In any case, more research is needed in these and other cities before a more complete picture is available. In addition, socio-historic data have been collected which shed light on the history of the sign community. These have been collected in different ways, including a sociolinguistic mapping exercise (Figure 1), collection of documents, and interviews with participants in all urban centres mentioned above. 


\subsubsection{Describing variation at different levels of linguistic organisation}

As with spoken languages, variants in sign languages can be found at different levels of linguistic organisation. Recently, sign language sociolinguists have made distinctions between phonological variants and lexical variants (Cormier et al. 2012). According to the use of these terms in the literature, phonological variants generally vary from each other in one parameter typically handshape, orientation, location, movement, or handedness - and have several formal elements in common. ${ }^{3}$ The implication is that phonological variants derive either from each other, or from a common original source, through processes associated with morpho-phonological variation and change. As per the concept of ID glossing (Johnston et al. 2011) these signs are grouped as a single lemma with the same gloss, and their status as phonological variants is shown with lower-case letters in the variant code to the right of the gloss (GLOSS:a, GLOSS:b).

Lexical variants differ from each other in more than one parameter, and have few, if any formal elements in common. The status of 'lexical variant' is indicated by numbers in the variant code (GLOSS:1, GLOSS:2). I assume that lexical variants either derive from different sources or have diverged from each other beyond recognition due to an accumulation of phonological changes. It is therefore necessary to consider the known or likely derivation of a sign when glossing. Inevitably, the determination of variants as phonological or lexical is not always clear, and in-between cases occur because the distinction is based on the degree of formal similarity. Nonetheless, the attribution of glosses should be motivated as far as possible by semantic and structural principles. The glossing process is often cyclical, especially when a language is being documented for the first time, and it may be necessary to revise glosses in light of new information.

In section 2 I aim to show that variants for colour terms are sometimes organised in a predictable way, united by similar motivations. The term 'lexical variant' does not in itself sufficiently describe this organisation, and so the notion of 'lexical sets' is introduced to describe lexical variants that relate to a particular semantic domain and share a common motivation or derivation. The forms of members of a lexical set are not arbitrary, but are united by an element of systematicity in their provenance or formal properties. An important corollary of this is that a variant should ideally be labelled in a way that highlights the distinct identity of its lexical set. If, for example, a set of variants for colour terms are derived in the same way from the same manual alphabet, they are given the same code (GREEN:init, BLUE:init etc.). 
An advantage of this is that glosses become easier to interpret, since the subscripts hold some clue as to the form of the respective variant.

\section{Non-initialised variants}

Of the 29 lexical variants produced by informants, 16 are initialised and 13 are not. There are reasons to believe that many non-initialised variants may be older than initialised ones. Whereas the use of initialised variants is motivated by written forms of colour terms and strongly associated with the education system (see section 3 ), the motivation for non-initialised variants is largely iconic, and these signs may therefore have emerged before most signers had access to education. A small number of non-initialised variants are common to both Makassar and Solo varieties (2.1), but most variants are particular to one variety or the other (2.2).

One of the ways in which colour terms may form is derivation, whereby 'the meaning of the sign for an entity with a typical colour is extended to include reference to the typical colour' (Nyst 2007:91). For some of the noninitialised variants described here, the iconic motivation is still apparent, but for others, it is no longer identifiable. In the following sections, when the motivation of a form is sufficiently clear, it is specified. The absence of such comments should be taken as indicating that the motivation is unknown.

\subsection{Variants common to both varieties}

Only three of the non-initialised variants produced by informants are common to both Makassar and Solo. These are HITAM ('black'), MERAH ('red') and COKLAT:1 ('brown'), shown in Figure 1 along with phonological variants. HITAM exploits the fact that Indonesians typically have black hair, and is used regardless of whether a signer has hair of a different colour (or no hair at all). MERAH and COKLAT:1 refer to the lips and the skin for the colours red and brown respectively.

All three lexical variants shown in Figure 1 are clearly motivated by iconicity, which explains why it is that these forms also occur in other, unrelated sign languages. For example, forms that are similar to HITAM and MERAH are found in Ban Khor Sign Language in Thailand (Nonaka 2004:750) and Kata Kolok (de Vos 2011:71). Although these variants derive from indexical signs that point to parts of the body, which are of course always available to 
the signer, they have become fully lexicalised, as indicated by their use alongside intensifiers, creating meanings such as 'very red' and 'quite red'.

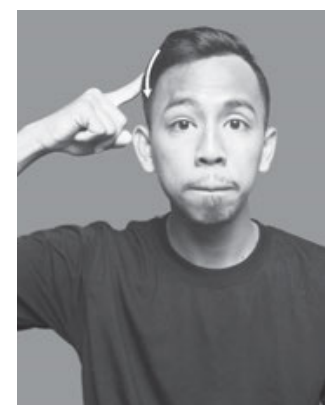

HITAM:a

('black')

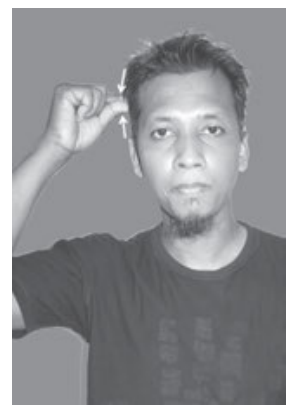

HITAM:b

('black')

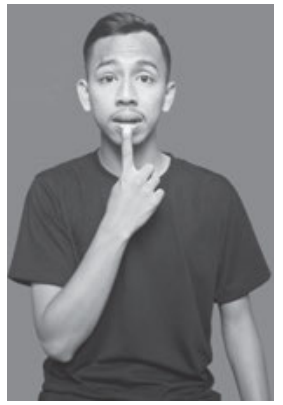

MERAH:a

('red')

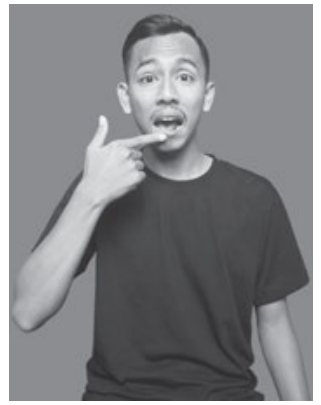

MERAH:b

('red')

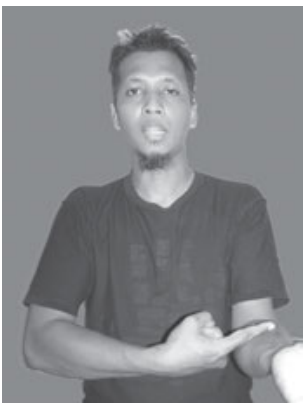

COKLAT:1

('brown')

Figure 1. Variants for the colours black, red and brown.

\subsection{Variants used in only one of the two varieties}

Ten of the non-initialised lexical variants are used by informants in only one of the two varieties. It seems that not all of these variants are known or used by all members of the sub-community in question. Some variants are older, while others are associated with a particular school, or have been introduced to Solo through contact with sign language varieties elsewhere in Indonesia.

Only one non-initialised sign was used in Makassar but not Solo: this is PINK:2 ('pink'), shown in Figure 2a. This variant is homophonous with another iconic sign, INDONESIA, which represents the red and white Indonesian flag, and PINK:2 seems to refer to a mix of these colours. Reference to a mixing strategy also occurs in Italian Sign Language, where some variants for 'pink' use the handshape of WHITE with the movement and location of RED (Silver-Swartz 2012:27). 
The variants PUTIH:1 ('white') and KUNING:1 ('yellow') are shown in Figure 2b. PUTIH: 1 is used across the Solo sub-community, while KUNING:1, an older and less prevalent variant, is produced by the middle finger quickly and repeatedly rubbing against the thumb. The origins and motivations of these signs are unknown. The prevalence of PUTIH:1 stands in marked contrast to the variant for 'white' listed in SIBI (PUTIH:sibi), which was not produced by any respondent in Solo or Makassar. This shows that, even in locations and for lexical domains where SIBI variants are sometimes produced, the impact of SIBI upon the active lexicon of sign language users is unpredictable, and for some signs, negligible.

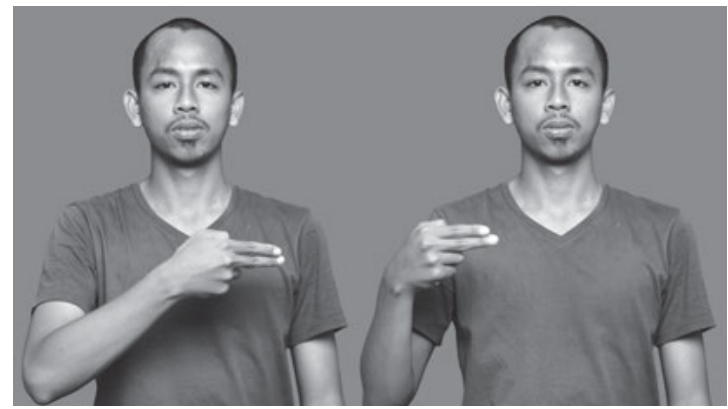

PINK:2 ('pink')

Figure 2a. A variant for 'pink' which is used in Makassar.

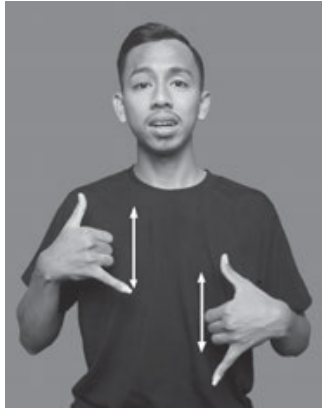

PUTIH:1

('white')

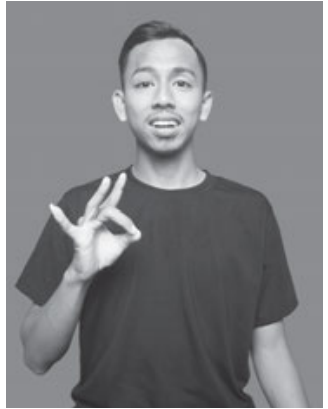

KUNING:1

('yellow')

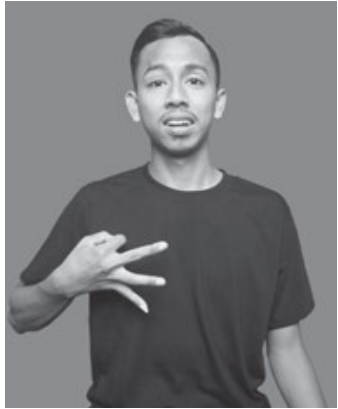

PUTIH:sibi

('white')

Figure $2 b$. Solo variants for 'white' and 'yellow', and the SIBI variant for 'white'.

An older variant used in Solo for the colour 'green' is discussed in 4.1. Meanwhile, two phonological variants for this colour that have emerged more recently are shown in Figure 3. These signs may be articulated below the nose, or under the chin. The orientation and internal movement also vary. One option is to flick the middle finger away from the thumb (HIJAU:1a), and another entails 
flicking the index finger away from the thumb, while keeping the other digits closed (HIJAU:1b). These variants are used by some signers in Solo, but are reported to have come from the city of Surabaya in East Java (see Map 1 above).

Another variant that informants described as a Surabayan variant for 'black', glossed HITAM:asl, does not seem to be used extensively in Solo, but is included here to show that colour terms from ASL have been borrowed, in this case exactly (Figure 3). Further evidence of this influence is presented in 3.2.

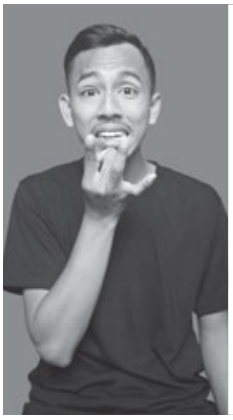

HIJAU:1a ('green')

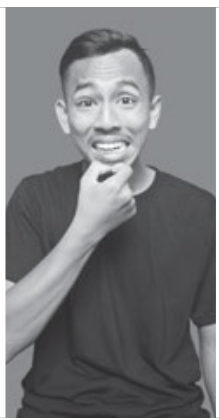

HIJAU:1b ('green')

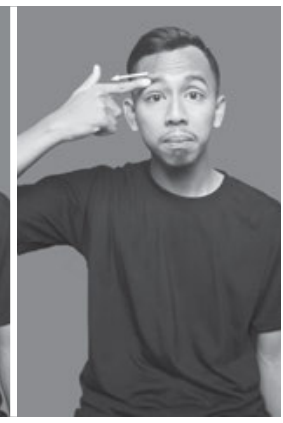

HITAM:asl ('black')

Figure 3. Variants reported to occur in the Surabaya variety; HIJAU:1a and $1 \mathrm{~b}$ also occur frequently in Solo; HITAM:asl does not.

Several other variants were produced in Solo for the colours grey, orange and purple (Figure 4). ORANYE:1 and UNGU:1 are reported to have been used in the schools YAAT and YRTRW respectively. ORANYE:1, ABU-ABU:1 and PINK:1c (Figure 10b) are very similar in terms of their phonological specifications, and it may be that this is essentially a generic sign with mouthings used to differentiate between them. ${ }^{4}$ In practice, non-initialised variants for the colours pink and grey seem to be notably unstable, and this is discussed further in section 6 .

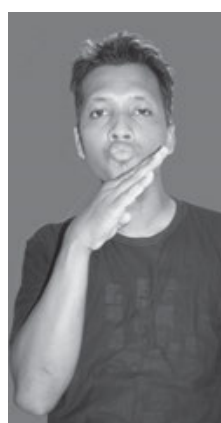

ABU-ABU:1

('grey')

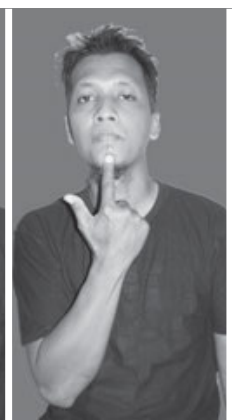

ABU-ABU:2

('grey')
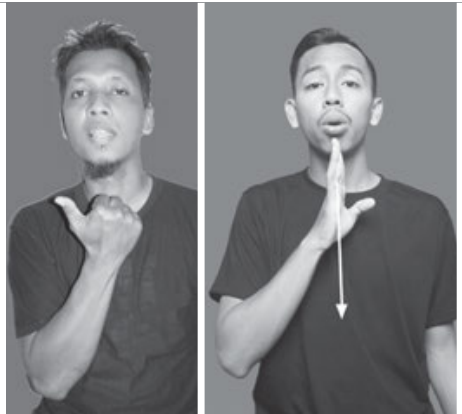

ORANYE: 1

('orange')

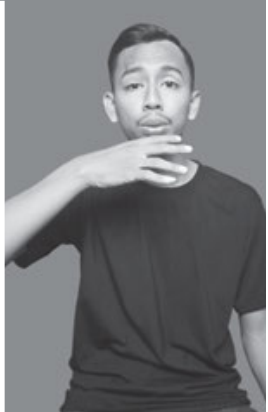

UNGU:1

('purple')

Figure 4. Idiolectal/school-based variants in Solo. 


\section{Initialised and single manual letter variants}

Initialisation has been attested in the colour terms of several sign languages, including ASL (Woodward 1989), Estonian Sign Language (ESL) (Hollman and Sutrop 2010) and New Zealand Sign Language (NZSL) (McKee, McKee and Major 2011). Initialised signs emerge in slightly different ways. Machabée (1995:34) notes that they may result from reducing a word spelt manually, or a change of handshape to an existing non-initialised sign. Initialised variants enter the lexica of sign languages as a result of contact with written language, usually through the education system.

This can be shown with respect to Kata Kolok, whose signers have only recently had access to formal education (de Vos and Palfreyman 2012). Prior to this, deaf signers in Bengkala were illiterate, and hence not in a position to make use of a manual alphabet. The international one-handed manual alphabet was only introduced for the education of deaf children in the village in 2007, and so initialised signs are not a part of the Kata Kolok lexicon (de Vos 2012:94).

In cases where language planners or educators introduce a set of initialised signs from one sign language to another, and the written language of the target community is different from that of the source community, the handshapes of initialised signs often change. This process is noted by de Garcia (1990:271) in Dominican Republic Sign Language for days of the week, where the handshapes used for signs in ASL, such as Monday and Friday, have changed from ' $\mathrm{M}$ ' and ' $\mathrm{F}$ ' to ' $\mathrm{L}$ ' and ' $\mathrm{V}$ ', for the Spanish lunes and viernes. This process has been used to create expressions for colour terms in SIBI, with handshapes used for initialised signs in ASL (such as 'G' for green) changed to match the corresponding word in Standard Indonesian ('H' for hijau) - see 3.2.

Manual alphabets belong to one of two types, one-handed and two-handed (Branson et al. 1995), and where a sign language uses a two-handed alphabet, initialisation is rare (Adam 2012:849). Instead, single manual letter signs are usually produced, whereby only the initial letter of the corresponding written word is signed (Sutton-Spence 1994). For the urban varieties of Indonesia, these are nearly always accompanied with a mouthing for the colour term in Standard Indonesian.

The existence of one-handed and two-handed alphabets in both sign language varieties means that some colour terms have two initialised variants, and so there are two lexical sets for initialised colour signs. Initialised variants based on the two-handed alphabet are presented in 3.1, and variants based on the one-handed alphabet in 3.2. However, not all of the letters in a so-called two-handed alphabet are actually represented with two hands, which leads to some ambiguity about which lexical set an initialised variant belongs to. This is discussed further in section 3.3. 
Technically, single manual letter variants are not initialised signs proper; they are, however, often referred to as almost a counterpart to initialised signs for varieties that use two-handed alphabets (Adam 2012:849). Additionally, in the data there is variation in the movements that are used to accompany 'initialised' signs. For variants in section 3.2, for example, the movement that properly distinguishes an initialised sign from a single manual letter variant seems to be optional, making it difficult to categorise these signs. With the similarities in mind, it makes sense here to consider single manual letter forms as 'initialised' in a loose sense.

It is usually difficult to tell whether an initialised variant has displaced an older, non-initialised sign. As Berlin and Kay (1969:44) point out, borrowing foreign forms for colour terms can either encode a colour term that was previously uncoded, or replace an existing form. In some cases, however, initialised variants persist alongside non-initialised variants that are described in section 2 . See section 5 for a brief discussion of how informants cope with these variants.

\subsection{Variants based on the two-handed manual alphabet}

Three initialised variants occur in both the Makassar and Solo varieties that are based on the two-handed manual alphabet (Figure 5). Note that, in this and subsequent figures that show initialised signs, letters that are represented manually are indicated in the gloss in bold type. init 2 refers to variants based on the two-handed alphabet, and initl to the one-handed alphabet.

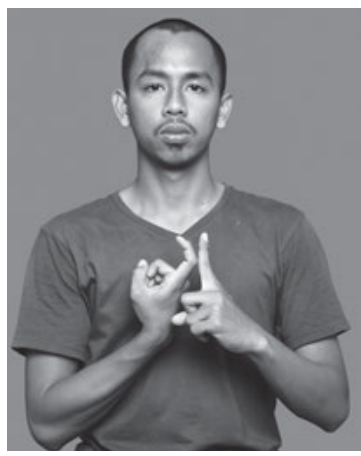

KUNING:init2

('yellow')

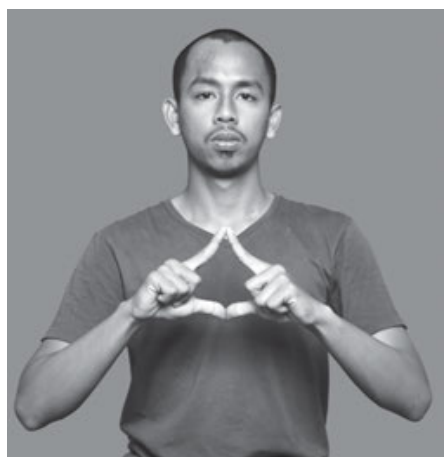

ABU-ABU:init2

('grey')

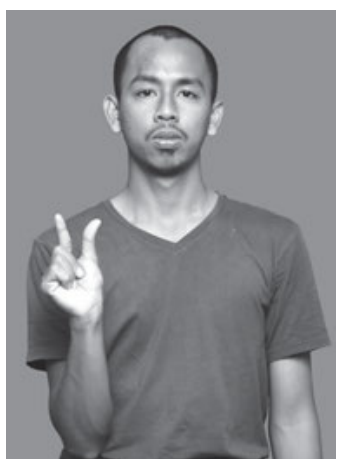

UNGU:init2

('purple')

Figure 5. Single manual letter variants used in both Makassar and Solo.

Conversely, the variants in Figure 6 are produced only by Makassarese informants. Although it is possible in theory for these to occur in Solo, which shares 
the same manual alphabet, non-initialised alternatives are produced in Solo in each case (see 2.2). BIRU:init2 ('blue') is exceptional in that two separate letters - B, a two-handed form, and R, a one-handed form - are blended by means of a hold in one of the hands, making it a 'two manual letter' variant. KUNING:init2m is notable for using a variant for the letter $\mathrm{K}$ that occurs in Makassar but not in Solo. While this form looks more similar to KUNING:init1 (Figure 7), it is actually closer, in terms of its origin, to KUNING:init2 (Figure 5).

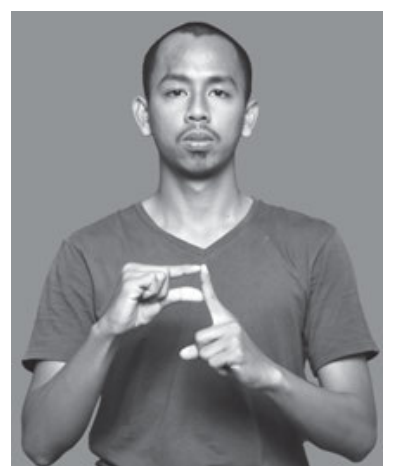

PUTIH:init2

('white')

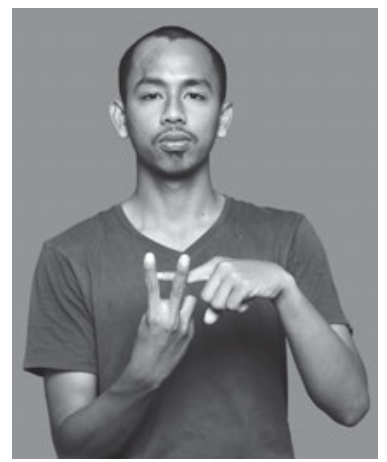

HIJAU:init2

('green')

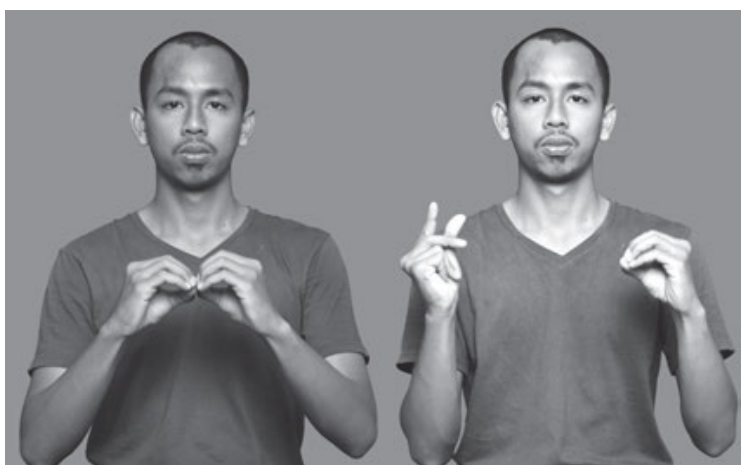

BIRU:init2 ('blue')

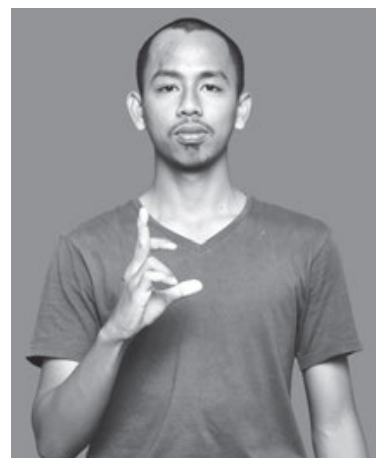

KUNING:init2m

('yellow')

Figure 6. Single manual letter variants observed only in Makassar.

\subsection{Variants based on the one-handed manual alphabet}

The variants for 'blue,' 'yellow,' 'green' and 'grey' all use handshapes from the one-handed manual alphabet for the initial letters of the corresponding words in Standard Indonesian (B, K, H and A respectively). This supports the notion that these comprise a distinct lexical set of colour variants. BIRU:init1 
and KUNING:init1 (Figure 7) have a fixed location and usually feature a twisting movement, while HIJAU:init1 and ABU-ABU:init1 tend not to feature any internal movement, but often have a small forward movement (twice, in the case of ABU-ABU:init1). In all cases, however, these signs are sometimes articulated without movement.

The same colour terms are also represented in SIBI as one-handed, initialised signs. The committee that drafted SIBI seems to have tried to create a lexical set of colour terms by using a method similar to l'Epée and Sicard in eighteenth-century Paris, who added a distinguishing movement to an alphabetic handshape (Stokoe 1987:9). This has not been entirely successful, because in practice, informants do not add the wavy downward movement that is specified for these colour signs in SIBI.

HIJAU:asl ('green') and PINK:asl - also shown in Figure 7 - are formally very similar to the equivalent signs in ASL. For HIJAU:asl, the initial handshape $(\mathrm{G})$ in the source language has been retained in the target language (i.e. from the ASL sign GREEN). The retention of this sign, which is at odds with the initialisation strategy - given that hijau does not begin with ' $\mathrm{G}$ ' - may be due to the stronger influence of ASL in the Surabayan variety, with which the Solonese variety has had contact. The occurrence of PINK:asl in the Solo dataset can also be explained in this way.

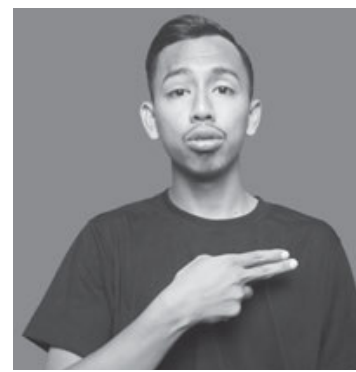

HIJAU:init1 ('green')

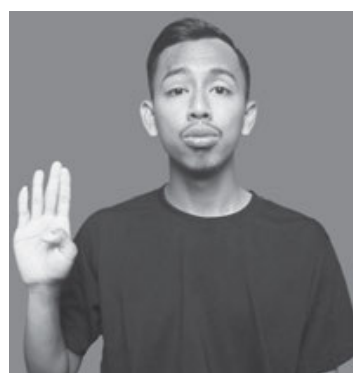

BIRU:init1 ('blue')

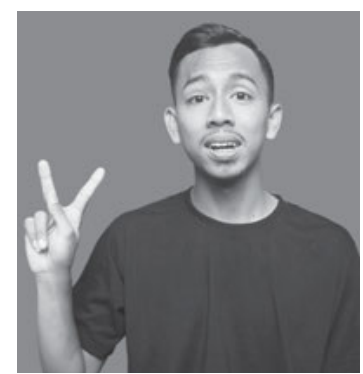

KUNING:init1 ('yellow')

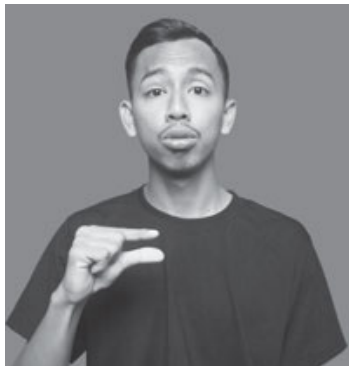

HIJAU:asl ('green')

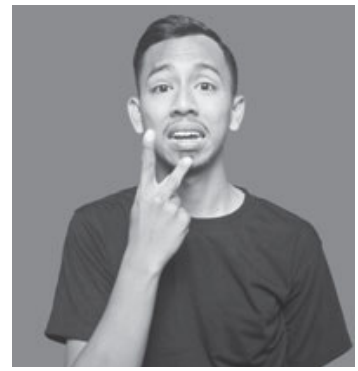

PINK:asl ('pink')

Figure 7. Initialised signs based on the one-handed manual alphabet. 


\subsection{Indeterminate variants}

The term 'two-handed alphabet' is itself somewhat misleading, given that nine letters in the Indonesian manual alphabet $(\mathrm{C}, \mathrm{I}, \mathrm{J}, \mathrm{L}, \mathrm{O}, \mathrm{R}, \mathrm{U}, \mathrm{V}, \mathrm{Z})$ are represented with one-handed forms, and others $(\mathrm{E}, \mathrm{K})$ have both one- and two-handed variants. The one-handed forms shown in Figure 8 are usually articulated with a circular movement. ORANYE:init-o and COKLAT:init have handshapes that can represent the letter ' $\mathrm{O}$ ' in both the one-handed and two-handed alphabets, which means that this variant could belong to either lexical sets of initialised variants. However, ORANYE:init-f can only belong to the two-handed lexical set, since this handshape represents the letter ' $F$ ' in the one-handed alphabet.

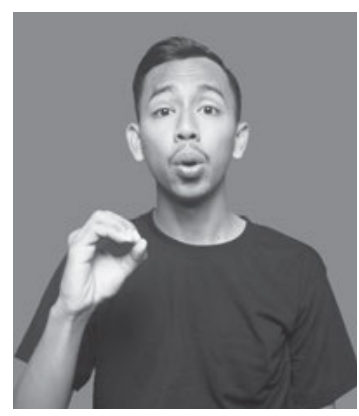

ORANYE:init-o

('orange')

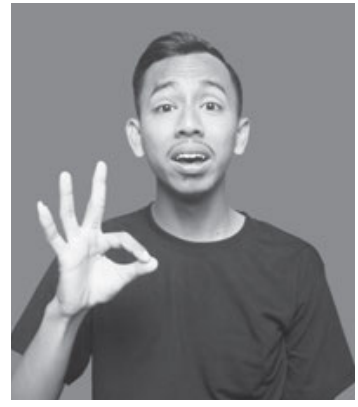

ORANYE:init-f

('orange')

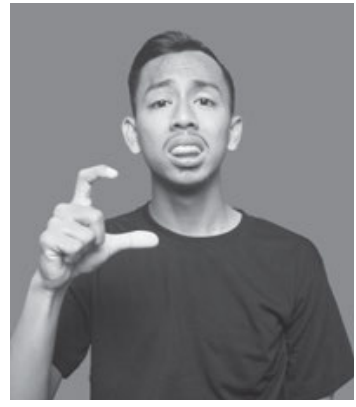

COKLAT:init

('brown')

Figure 8. Initialised signs based on letters identical in form in both alphabets.

\section{The impact of language contact on the inventory of colour terms}

It is far from inevitable that a sign language will possess the same inventory of colour terms as its surrounding spoken language. For example, colour terms in Kata Kolok differ considerably from Balinese. Whereas Balinese has 11 colour terms, Kata Kolok has just four lexical signs: WHITE, BLACK, RED, and GRUE - the latter describes the colours blue and green (de Vos 2011). As with the lack of initialised signs in Kata Kolok, however, this is perhaps due in part to the fact that deaf signers in Bengkala did not have access to formal education until very recently, and de Vos suggests that the use of a sign language in formal deaf education 'might accelerate the calibration of colour signs to the colour words of the surrounding spoken language' (de Vos 2011:75). 
For urban sign language varieties in Indonesia, which are used by subcommunities that have had access to formal education for some time, the inventory of colour terms seems to correspond more closely to the range of terms in Standard Indonesian. There are indications in the data of two changes that are currently underway in the inventory of colour terms, and in each case, the evidence comes from co-existing variants. In section 4.2, variability in the expression of the colour pink is discussed. Before that, I examine a single variant that informants produce in response to colour tiles for both green and blue.

\subsection{Variants meaning 'blue' and 'green'}

When asked for variants for the colour green, three informants in Solo produced HIJAU/BIRU:a and HIJAU/BIRU:b (Figure 9), and my research consultants identify these variants as older signs. The two variants that were produced are nearly identical, but have different orientations. The same pair of variants was also given by two informants in Jakarta. However, two Solonese informants produced similar forms (HIJAU/BIRU:a and HIJAU/ BIRU:c) for the colour blue. These informants usually used an alternative variant, HIJAU:2a, for green. In each of the cases described above, informants reinforced the meaning of the sign that they were producing by using an appropriate mouthing from Standard Indonesian. ${ }^{5}$

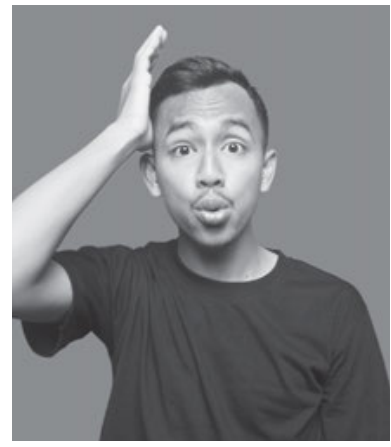

HIJAU/BIRU:a

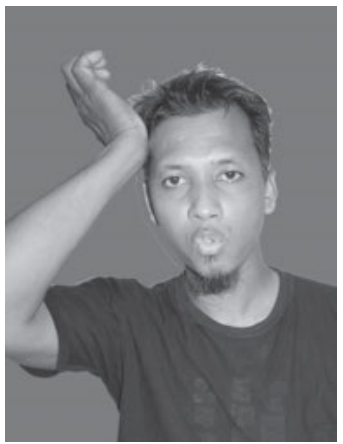

HIJAU/BIRU:b

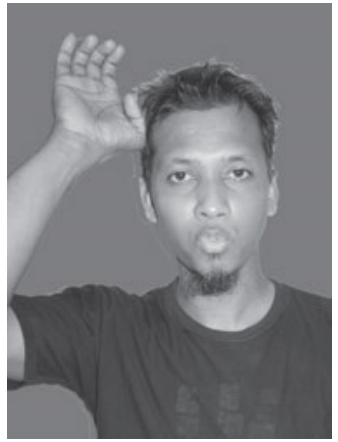

HIJAU/BIRU:c

Figure 9. Phonological variants for green and blue. Variants $a$ and $b$ differ in orientation (in $\mathrm{b}$ the hand is almost perpendicular to the wrist); variants $a$ and $c$ differ in handshape (in $\mathrm{c}$ the thumb is tucked in front of the palm).

This phenomenon could be linked to changes in the inventory of colour terms in the dominant spoken language. At the beginning of the twentieth century, 
Javanese was dominant in most of Java, but by the end of that century the dominant language had shifted to Bahasa Indonesia. In his dictionary of Old Javanese, Zoetmulder (1982) translates ijo/hijo as 'green, also blue', although there seems to have been another distinct term for blue which may or may not have been a borrowing from English or Dutch (see Berlin and Kay 1969:88). The conflation of blue and green is also noted by Bartlett (1929:16), who reports an 'underlying tendency to confuse blue with green', as seen in the 'use of idjo toewo (dark green) for a distinctly bluish grey'. While the Javanese term for green seems to have included the colour blue, Standard Indonesian now encodes blue and green as separate colour terms.

It may be that a similar process has taken place in the inventory of colour signs, with distinct forms meaning blue and green having replaced an earlier form meaning 'blue-green'. Interestingly, while there are other non-initialised variants for green (see 2.2), HIJAU/BIRU is the only non-initialised variant for blue that occurs in the data, and other variants for blue in Makassar and Solo rely on borrowing/initialisation (3.1 and 3.2). This means that an older form could have narrowed semantically in different ways, with some signers now using it to correspond with 'green' (using another sign for 'blue') and some signers using it to correspond with 'blue' (using another sign for 'green'). This is still a hypothesis, and more research is needed to test it.

\subsection{Variants meaning 'pink'}

A more incontrovertible example of language contact affecting the inventory of colour terms can be seen in variation for the colour pink. Berlin and Kay (1969:44) report that Malay/Indonesian lacks a term for 'pink', and Indonesian speakers commonly use merah muda or merah jambu, which include and modify the term merah ('red'). ${ }^{6}$ However, many younger speakers now borrow the English term pink, which is regarded as being more prestigious than the Indonesian equivalents (Noor Malihah, personal communication, January 2014). This is in line with positive evaluations of other borrowings from English (Lamb and Coleman 2008).

Following Malay/Indonesian, several signers express the colour pink with two manual signs MERAH MUDA and the mouthing 'merah muda' - see Figure 10a. However, some of the informants who know of the borrowing pink use 'pink' as the mouthing instead. The manual lexical variants that this mouthing accompanies are monolexemic. Two phonological variants are shown in Figure 10b, and lexical variants can be seen in Figures 2a and 7 (the latter is initialised). It seems that contact with Malay/Indonesian - and the 
different possibilities that it offers for expressing 'pink' - has had a notable effect on manual signs and mouthings in both sign language varieties.

There is still confusion among some signers concerning expressions for 'pink'. Even though the variants and mouthings described above are produced by signers in response to the same colour tile, one Makassarese signer insisted that MERAH MUDA and PINK:2 are not interchangeable, but that MERAH MUDA means 'merah muda' and PINK:2 means 'pink'. This shows that caution must be taken when using written languages as stimuli for elicitation, and is also another indication of how some signers may perceive variation in the colour signs of sign language through variation in spoken language. These perceptions arguably raise methodological questions for sign linguists working on colour terms that are not easily answered.

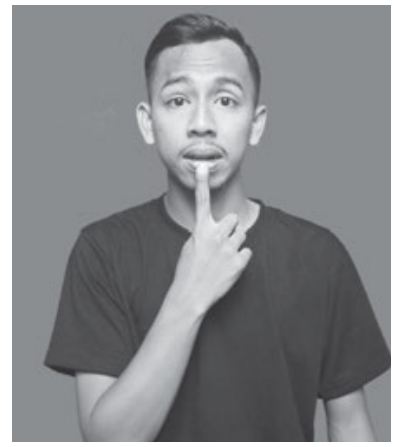

MERAH
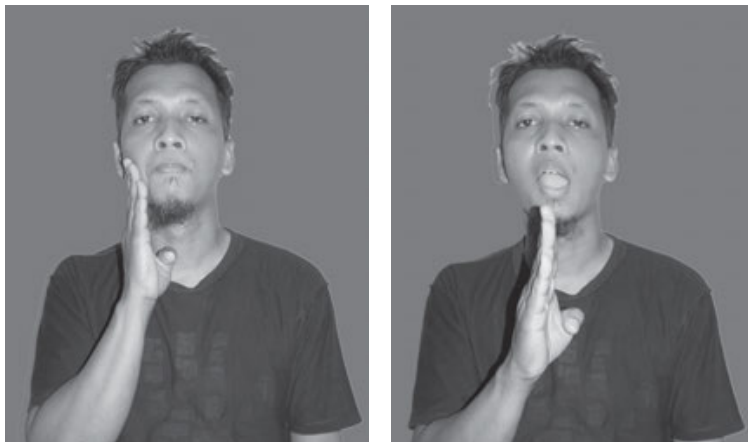

MUDA

Figure 10a. An expression for the colour pink (meaning 'light red').

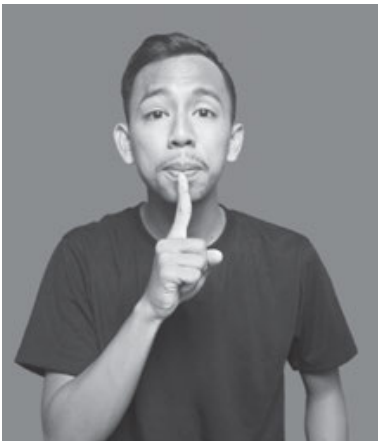

PINK:1a

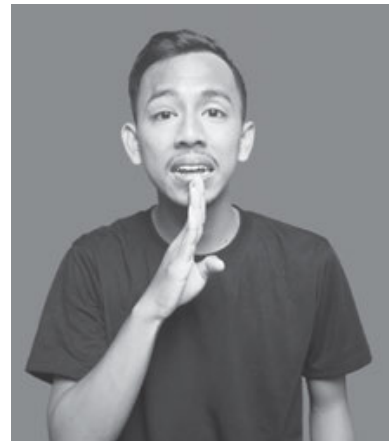

PINK:1c

Figure 10b. Mono-lexemic variants for the colour pink in Solo. 


\section{Coping with variation}

How do sign language users cope with the different variants for colour terms described in sections 2-4? In some cases, it is clear that informants have a passive knowledge of variants other than the one(s) that they usually produce. For example, one of the Solonese informants, aged 36, was able to list all of the four variants for 'green' that have been found for the Solo variety. However, his 21-year-old friend had never seen one of these variants (HIJAU/BIRU:a) before, and initially mistook this for a sign with a similar form that means 'don't understand'.

In other words, while some informants know and use more than one variant, other informants may know only a limited selection of variants, and seem to have a clear preference as to which variant they use. This in turn points to considerable diversity in the constellations of variants that constitute the active and passive lexicons of sign language users, regardless of how large the pool of variants is in the city where they live.

When dealing with the challenges posed by multiple variants, or lexical sets, one of the strategies that signers sometimes use in the data entails stacking variants one after another, presumably to maximise the chances that the other signer will recognise one of these variants (see Palfreyman, 2015 for more discussion of this strategy). This can be seen in (1) where an informant uses two different variants for the colour yellow.

\begin{tabular}{|c|c|c|c|c|}
\hline & kuning & \multicolumn{2}{|l|}{ kuning } & kuning \\
\hline $\begin{array}{l}\text { PINTU } \\
\text { door } \\
\text { 'The do }\end{array}$ & $\begin{array}{l}\text { KUNING:init1 } \\
\text { yellow } \\
\text { is yellow.' }\end{array}$ & $\begin{array}{l}\text { KUNING:init2 } \\
\text { yellow } \\
\text { It is light yell }\end{array}$ & $\begin{array}{l}\text { MUDA } \\
\text { light } \\
\text {.' }\end{array}$ & $\begin{array}{l}\text { KUNING:init2 } \\
\text { yellow }\end{array}$ \\
\hline
\end{tabular}

Another strategy is to fingerspell a variant using one of the two manual alphabets. Informants seem to use this strategy either when they are unsure of the form that they feel they should use, or are uncertain that their interlocutor will understand it:

$\begin{array}{ll}\frac{\text { kucing }}{\text { KUCING }} & \begin{array}{l}\text { FS:ABUA-abu } \\ \text { cat }\end{array} \\ \text { grey }\end{array}$

The cat is grey. 
The use of mouthing is reported to have a role to play in facilitating the intelligibility manual variants for colour terms. Stamp (2013) notes that British Sign Language (BSL) users seem to rely heavily upon mouthings in order to understand regional variants for colour terms. Without mouthings, the average participant in her dialect comprehension task was able to correctly identify only $38 \%$ of colour sign meanings in British Sign Language (Stamp 2013:178). Almost all colour terms in the Indonesian data occur with a mouthing, but there are nevertheless occasions where mouthing fails to prevent the inaccurate comprehension of a colour term variant.

Example (3) describes an example of a misunderstanding that occurs between two friends during an activity designed to generate tokens of colour terms. This incident seems to occur because they do not have - or at any rate, do not happen to use - a mutually intelligible term for 'pink'. Even once the mistake has been identified, they continue to use several different variants. Over the next fifteen minutes of the game, a further 31 tokens of variants for 'pink' are used, with five different variants, and only then do the signers synchronise fully, henceforth using MERAH:a for pink and MERAH:b for red.

(3) An example of inaccurate comprehension of colour term variants.

Ari describes the colours of a picture. Muhammad cannot see the picture, but must select a matching colour tile, based on Ari's description, from a set of tiles.

Ari describes a shade of pink using MERAH:a ('red') and a mouthing 'jambu, jambu' (see section 4.2, and note 6).

Muhammad interprets MERAH:a as a variant for grey, and repeats it with the mouthing 'abu-abu' (meaning 'grey'). With no negative feedback from Ari, he selects a grey tile.

Later they compare the picture with the tiles that Muhammad has selected.

Muhammad notices that the colour Ari had been describing was pink, not grey.

Ari points out that Muhammad has selected grey (ABU-ABU:init1) which is different from pink (MERAH:a). In reaffirming that Muhammad has selected a grey tile, he clarifies the signs that he would have used for grey had he intended to describe grey (using both $\mathrm{ABU}-\mathrm{ABU}$ :init1 and $\mathrm{ABU}-\mathrm{ABU}:$ init2).

It seems that 'pink' is a particularly problematic colour term at the moment, and this may be because of the array of different options for manual variants and mouthings discussed in 4.2. 
Other colours that occur during the course of the activity do not present this kind of problem. When Muhammad produces a variant for 'blue' (HIJAU/BIRU:a) that Ari does not recognise, Ari seems able to identify the sign successfully from the mouthing that Muhammad uses. However, Ari corroborates this, responding questioningly with HIJAU:2a and BIRU:init1 in order to see which colour is intended, and Muhammad responds by repeating BIRU:init1. Later on, Muhammad produces a hitherto unused variant for 'green' (HIJAU:asl) and Ari uses the same strategy as before, confirming the meaning by using HIJAU:2a in reply. Importantly, BIRU:init1 and HIJAU:2a are now 'stable' variants in this conversation - they have already occurred in the dialogue, and both signers understand what these variants signify. Consequently, Ari's corroboration strategy is successful.

To summarise, several strategies are used to cope with variation, including fingerspelling, and the production of more than one variant in the same utterance. Mouthings play a key role in the disambiguation of manual variants for colour terms. Some signers also corroborate their understanding of a certain variant by producing, in response, a different variant for the same colour term, often with interrogative facial expressions. Questions of intelligibility and strategies for coping with variation are discussed further in Palfreyman (2015).

\section{Discussion}

As with other semantic domains, such as numerals (Palfreyman forthcoming), lexical variants for colour terms are organised as sets. Three lexical sets have been found: non-initialised variants; single manual letter variants based on the two-handed indigenous alphabet; and initialised variants based on the imported one-handed alphabet. This is summarised in Table 1. Within the first set, a further class of variants can be found that are motivated by canonical colours typically associated with body parts (HITAM, MERAH and COKLAT:1).

The Solo data exhibit more lexical variation than the Makassar data, but both datasets usually contain at least two variants per colour term, one of which is more recent - usually an initialised sign - and one of which is older. Initialisation is the most common strategy for colour terms in Makassar, but the use of the indigenous two-handed manual alphabet creates a strong contrast with the lexical set that is based on the one-handed manual alphabet. Although there are differences in the precise constellation of variants for colour terms that occur in Makassar and Solo, all three lexical sets are evident in both varieties. 
Table 1. Lexical variants for colour terms in the sign language varieties of Makassar and Solo.

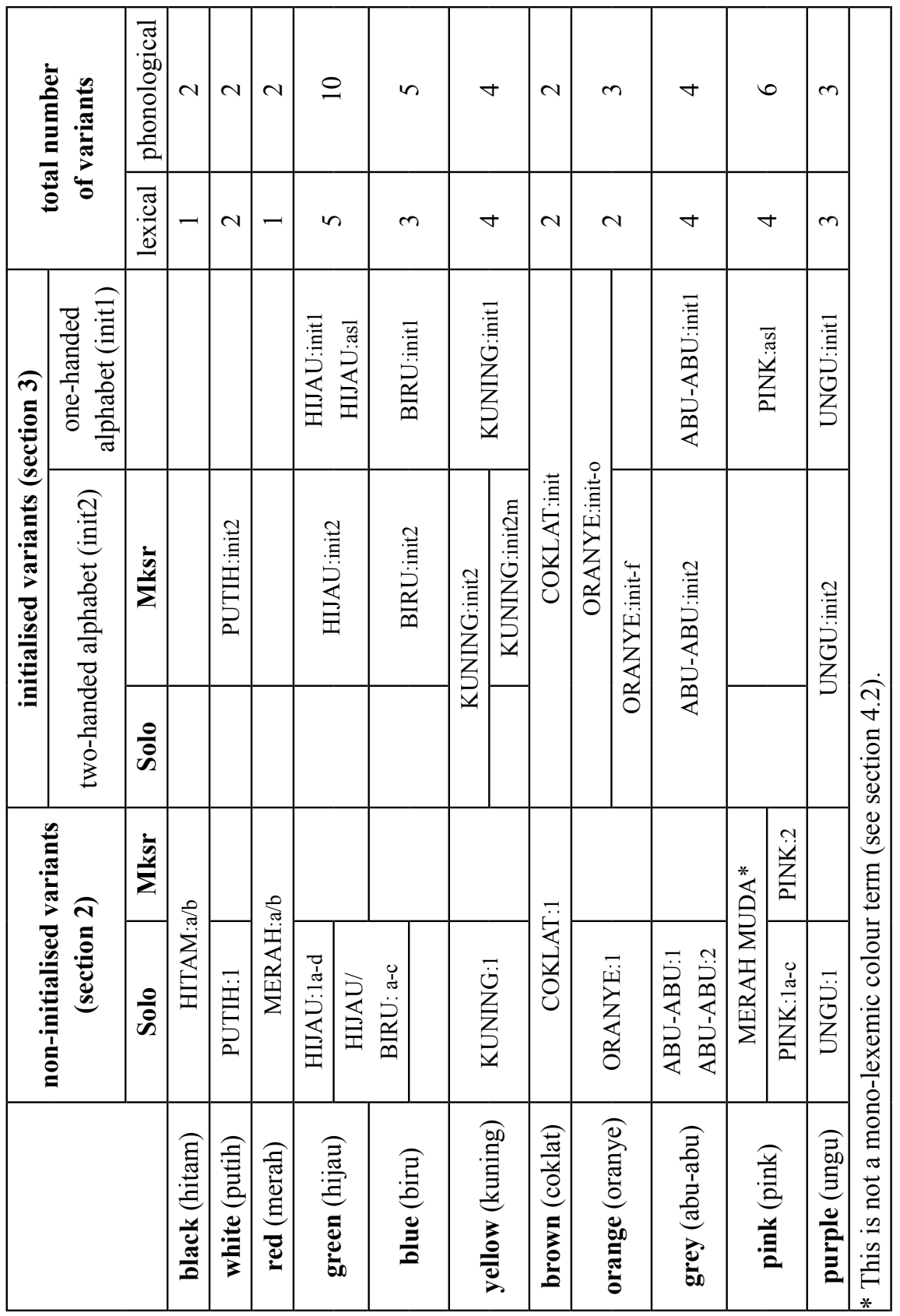


The issue of lexical stability has emerged several times, both in terms of the number of idiolectal variants (section 2.2) and the difficulty that occasionally arises when expressing some colour terms (section 5). Further, while at least four lexical variants are produced for 'yellow', 'grey' and 'pink' and five for 'green' - two colour terms ('red' and 'black') exhibit no lexical variation, and both of these are highly motivated by iconicity. Where the representation of a semantic item is strongly motivated by a clear iconic source, it seems less likely that there will be other variants with which it competes, and this seems to be typified cross-linguistically by the colour terms 'red' and 'black'.?

There is evidence to suggest that a shift is taking place towards initialised signs for colour terms. Older sign language variants are sometimes referred to by Indonesian signers as isyarat lama, or 'old signs'. According to the research consultants, many of the non-initialised signs described in section 2 are isyarat lama, not used or known by some younger signers. This is exemplified by the 21-year-old signer who did not recognise the sign HIJAU/ BIRU:a (mentioned at the beginning of section 5).

Instead, it seems that younger signers tend to produce initialised variants for most colour terms that draw upon the one-handed alphabet (section 3.2), though expressions for 'red' and 'black' are not disposed to initialisation. Further, use of the two-handed alphabet remains strong in Makassar. With these points in mind, it is hypothesised that - for the Solo variety - the expression of many (though not all) colour terms is changing in favour of initialised signs, and quantitative research is now needed to test this hypothesis.

\subsection{Variation and lexical sets}

Lexical sets do not only occur in the semantic domain of colour terms. Another example in the corpus is signs for Javanese cities, where two sets currently coexist. The older set comprises signs that are based on the first letter(s) of vehicle registration plates which in Indonesia denote where the vehicle is registered. For example, Jakarta is signed as 'B', Yogyakarta is 'AB' and Surabaya is ' $\mathrm{L}$ '. This lexical set is in the process of being displaced by a new set, where cities are represented by signs that refer to their most prominent statue.

There are several descriptions in the literature of other instances of lexical sets, such as weekdays in NZSL. According to McKee and McKee (2011:505) one lexical set is based on naming the days by a routine domestic activity, while a second set, introduced in 1979, uses initialised signs. Coincidentally, 
at least three lexical sets for weekdays in the Makassar and Solo varieties have very similar motivations to those in NZSL.

Semantically, lexical sets of variants share certain characteristics. They develop around groups of semantically-related items that can be represented metonymically in different ways. These items tend to have either several possible iconic sources, as is the case with Javanese cities, or no clear iconic sources, as with weekdays. Lexical sets often emerge in schools through a process of 'schoolisation', and schools are also an important influence on the spread of initialised signs.

I would argue that the playfulness and inventiveness of sign language users also has a role to play in the origin and development of lexical sets, perhaps along with the satisfaction evoked by an extensive lexical set that can be extended to represent a group of semantic items. In some cases, it is likely that the longevity of a lexical set of variants can be explained by social identity. The indexical value of lexical sets that are linked to certain schools or social networks can help to explain both the persistence of older sets and, in some cases, the need for new ones.

\subsection{Further research}

The investigation presented in this chapter is far from exhaustive, and there is little doubt that further research on these and other varieties across Indonesia will uncover many more variants for colour terms. Given the sheer size and population of the Indonesian archipelago, there is every reason to suppose that, when other urban centres are added, the overall pool of colour term variants will be considerably larger than the 29 lexical variants reported here. Only after extensive documentation will it be possible to examine the way in which these variants pattern regionally.

Further documentation is time-sensitive because older variants for colour terms are disappearing, to be displaced by more recent variants. In particular, the Surabayan variant has been mentioned several times. In addition to borrowing signs from ASL in the 1980s, other variants such as those for 'green' (HIJAU:1a-d) appear to have emerged since. The chance to identify isyarat lama that pre-date the introduction of ASL signs will soon be lost.

Several hypotheses have been proposed here, concerning changes to the inventory of colour terms for 'green' and 'pink', and the shift towards the lexical set of one-handed initialised variants in the Solo variety. Both of these require testing with further data elicitation and quantitative analysis in order to establish which changes are taking place in the lexicon. 
Another area where research is needed concerns the hedging or modification of colour terms. Several such expressions have been observed, including signs that mean 'young', 'old', 'light', 'dark', 'strong', 'soft', 'little' and 'average'. While some of the terms are also used in Standard Indonesian, others are not. Further research is needed in order to ascertain the use and distribution of these terms.

Finally, more research is needed on the intelligibility of colour signs across regional varieties. Several strategies are observable in the way that signers deal with lexical variation in this semantic domain, including fingerspelling, mouthing and the stacking of different variants. Thus far, however, the analysis has been limited to signers in the same urban centre, and the intelligibility of colour terms between Makassarese and Solonese signers has not yet been investigated.

\section{Summary}

The vast majority of colour terms in the sign language varieties of Makassar and Solo may be expressed using several lexical variants, and this appears to be typical of sign languages cross-linguistically. Twenty-nine signs for colour terms produced by signers from Makassar and Solo are analysed as belonging to three lexical sets of variants: two of these sets feature initialised signs, and one does not. The two varieties contain at least two variants per colour term, and it is hypothesised that younger signers may prefer initialised signs that draw upon the one-handed manual alphabet. Several older, noninitialised signs, which are motivated by iconicity and derivation, tend to be known and used only by older signers.

Some signers use the same lexical variant (HIJAU/BIRU) to express both 'green' and 'blue', and it is possible that signers may originally have made no distinction between the two. It is also reported that expressions for 'pink' have changed, with signers using mono-lexemic variants rather than MERAH MUDA ('light red'), and the likely explanation for this is contact with Standard Indonesian. It seems that urban sign language varieties of Indonesia are more inclined to correspond with colour terms in the surrounding spoken language than are rural sign languages such as Kata Kolok. 


\section{Acknowledgements}

This research has been possible due to grants from the Gallaudet University Alumni Association's Graduate Fellowship Fund, and CBM International.

I gratefully acknowledge the cooperation of Gerkatin (the Indonesian Association for the Welfare of the Deaf). I thank all of my informants in Solo, Makassar, Jakarta, Banjarmasin and Manado, and in particular my three deaf research consultants - Muhammad Isnaini, Oktaviani Wulansari and Jayeng Pranoto - for their insights, patience and support. I would like to thank Ulrike Zeshan, Keiko Sagara, Katerina Finnis, Laura Wijaya, Adhi Kusuma, Harald Hammarström, Stuart Robson, Noor Malihah, Rose Stamp, Margaret Palfreyman, Tashi Bradford, Connie de Vos and Jenny Webster for their comments and support. Thanks to M. Fathoni Ryanto, Andi Arfan, Muhammad Adam Malik, Rini Ayu Lestari, Agus Jarwanto and Muhammad Isnaini for supplying the photographs. I take full responsibility for any errors herein.

\section{Notes}

1. Variation is evident in the data on colour terms on the website of the Corpus Project in Colloquial Japanese Sign Language, which is available at http:// research.nii.ac.jp/jsl-corpus/en/ (accessed 12 June 2014).

2. This is not the place for a lengthy critique of SIBI, but briefly, it does not exhibit the affordances of natural sign language varieties used by members of the deaf community, and its lexicon and grammar are largely unintelligible to deaf people. Even in schools where SIBI is heavily used, deaf children who are able to render a written sentence in manual form, and vice versa, do not always understand the meaning of the sentence.

3. Thus far, more attention has been paid to differences between parameters as they are produced, and the question of how these differences are perceived has yet to be seriously considered.

4. It is intriguing to note that so many signs for colour terms are located on the chin (see the variants shown in Figure 4, for example). Almost all variants for the superordinate term 'colour' also have this location.

5. All of the forms shown in Figure 9 are older signs, and are not produced at all by some of the other informants in Solo. These signs are not used at all by Makassarese informants.

6. Merah muda is equivalent in English to 'light red'. Jambu is a pink-coloured fruit called a rose apple, and merah jambu is named after this. 
7. 'Red' features no lexical variation in recent studies on German Sign Language (Eichmann and Rosenstock 2014), and Italian Sign Language (Silver-Swartz 2012), which accords with the findings here on Indonesian sign language varieties. In the same studies, the colour term 'black' is also typified by remarkably few variants.

\section{References}

Adam, Robert. 2012. Language contact and borrowing. In Roland Pfau, Markus Steinbach and Bencie Woll (eds.), Sign language: An international handbook. De Gruyter: Berlin. 841-861.

Bartlett, H. H. 1929. 'Color nomenclature in Batak and Malay.' Papers of the Michigan Academy of Sciences, Arts and Letters. 10:1-52.

Berlin, Brent and Paul Kay. 1969. Basic color terms: Their universality and evolution. Berkeley: University of California Press.

Bharoto, Adhi Kusuma. 2013a. Ygoyakarta Sign Language Dictionary. Jakarta: University of Indonesia Press.

Bharoto, Adhi Kusuma. 2013b. Classifier constructions in the Yogyakarta variety of Indonesian Sign Language. A paper presented at the Third International Conference on Sign Linguistics and Deaf Education in Asia, CUHK, 31 January - 2 February 2013.

Badan Pusat Statistik (BPS) [Indonesian Statistics Bureau]. 2012. Sensus Penduduk 2010 [2010 Populatio Census]

Branson, Jan and Don Miller. 2004. The cultural construction of linguistic incompetence through schooling: Deaf education and the transformation of the linguistic environment in Bali, Indonesia. Sign Language Studies, 5:1 (Autumn). 6-38.

Branson, Jan, Jennifer Toms, Brian Bernal and Don Miller. 1995. The history and role of fingerspelling in Auslan. In: Heleen Bos and Trude Schermer (eds.) Sign Language Research 1994: Proceedings of the fourth European Congress on Sign Language Research. Hamburg: Signum Press, 53-68.

Chu, Kenny and Laura Lesmana Wijaya. 2013. The linguistic and sociocultural aspects of name signs: a comparison between Hong Kong Sign Language (HKSL) and Indonesian Sign Languages (Jakarta). A paper presented at the Third International Conference on Sign Linguistics and Deaf Education in Asia, CUHK, 31 January - 2 February 2013.

Cormier, Kearsy, Jordan Fenlon, Trevor Johnston, Ramas Rentelis, Adam Schembri, Katherine Rowley, Robert Adam and Bencie Woll. 2012. From corpus to lexical database to online dictionary: Issues in annotation of the BSL Corpus and the development of BSL SignBank. Poster presented at the 5th Workshop on the representation and processing of sign languages: Interactions between corpus and lexicon. Istanbul, Turkey, 27 May 2012. 
de Garcia, Barbara Gerner. 1990. The emerging deaf community in the Dominican Republic: An ethnographic study. In Ceil Lucas (ed.), Sign language research: Theoretical issues. Washington DC: Gallaudet University Press. 259-74.

de Vos, Connie. 2012. Sign-spatiality in Kata Kolok: How a village sign language in Bali inscribes its signing space. PhD dissertation. Radboud University, Nijmegen, the Netherlands.

de Vos, Connie. 2011. 'Kata Kolok color terms and the emergence of lexical signs in rural signing communities.' The Senses \& Society 6:1 68-76.

de Vos, Connie and Nick Palfreyman. 2012. [Review of the book Deaf around the World: The impact of language / ed. by Mathur \& Napoli]. Journal of Linguistics, 48, 731-735.

Eichmann, Hanna and Rachel Rosenstock. 2014. Regional variation in German Sign Language: The role of schools (re-) visited. Sign Language Studies 14:2, 175-202.

Hollman, Liivi and Urmas Sutrop. 2010. Basic Color Terms in Estonian Sign Language. Sign Language Studies, 11:2 (Winter), 130-157.

Isma, Silva Tenrisara Pertiwi. 2012. Signing varieties in Jakarta and Yogyakarta: Dialects or separate languages? MA dissertation. CUHK, Hong Kong.

Johnston, Trevor, Adam Schembri, Kearsy Cormier, Jordan Fenlon and Ramas Rentelis. 2011. Type/token matching in annotated sign language corpora: Examples from Auslan and BSL corpus projects. Building Sign Language Corpora in North America workshop, Gallaudet University, 21-22 May 2011.

Johnston, Trevor (ed.). 1998. Signs of Australia: A new dictionary of Auslan. Sydney: North Rocks Press.

Chu, Kenny and Laura Lesmana Wijaya. 2013. The linguistic and sociocultural aspects of name signs: a comparison between Hong Kong Sign Language (HKSL) and Indonesian Sign Languages (Jakarta). A paper presented at the Third International Conference on Sign Linguistics and Deaf Education in Asia, CUHK, 31 January - 2 February.

Lamb, Martin and Hywel Coleman. 2008. Literacy in English and the transformation of self and society in post-Soeharto Indonesia, International Journal of Bilingual Education and Bilingualism, 11, 189-205.

Leeson, Lorraine and Carmel Grehan. 2004. 'To the lexicon and beyond: The effect of gender on variation in Irish Sign Language.' In: Mieke van Herreweghe and Myriam Vermeerbergen (eds.) To the lexicon and beyond: Sociolinguistics in European deaf communities. Washington, DC: Gallaudet University Press. 39-73.

Le Master, Barbara and John P. Dwyer. 1991. Knowing and using female and male signs in Dublin. Sign Language Studies 73, 361-9.

Marsaja, I Gede. 2008. Desa Kolok: A deaf village and its sign language in Bali, Indonesia. Nijmegen: Ishara Press. 
Machabée, Dominique. 1995. Description and status of initialised signs in Quebec Sign Language. In Ceil Lucas (ed.), Sociolinguistics in deaf communities. Washington DC: Gallaudet University Press. 29-61.

McKee, Rachel and David McKee. 2011. 'Old signs, new signs, whose signs?' Sociolinguistic variation in the NZSL lexicon. Sign Language Studies (Summer) 11:4.

McKee, David, Rachel McKee and George Major. 2011. Numeral variation in New Zealand Sign Language. Sign Language Studies 12:1 (Autumn) 72-97.

Nonaka, Angela. 2004. Sign languages - the forgotten endangered languages: Lessons on the importance of remembering. Language in Society (33:5) 737-767.

Nyst, Victoria. 2007. A descriptive analysis of Adamorobe sign language (Ghana). $\mathrm{PhD}$ dissertation, University of Amsterdam.

Palfreyman, Nick. forthcoming. Variation and change in the expression of numerals across urban sign language varieties in Indonesia.

Palfreyman, Nick. 2015. Sign language varieties of Indonesia: A linguistic and sociolinguistic investigation. $\mathrm{PhD}$ dissertation, University of Central Lancashire, UK.

Palfreyman, Nick. 2013. Form, function, and the grammaticalisation of completive markers in the sign language varieties of Solo and Makassar. In John Bowden (ed.), Tense, aspect, modality and evidentiality in languages of Indonesia. NUSA 55 (Autumn) 153-172.

Quinn, Gary. 2010. Schoolization: An Account of the Origins of Regional Variation in British Sign Language. Sign Language Studies 10:4 (Summer) 476-501.

Silver-Swartz, Amira. 2012. Lexical variation in Italian Sign Language. Senior thesis, Swarthmore College, Pennsylvania.

Stamp, Rose. 2013. Sociolinguistic variation, language change and dialect contact in the British Sign Language (BSL) lexicon. PhD dissertation, UCL, London.

Stokoe, William. 1987. Lexical indicators of cultural change. In Jim Kyle (ed.), Sign and School: Using Signs in Deaf Children's Development. Multilingual Matters: Clevedon. 7-11.

Sukmara, Galuh. 2014. A phonological description of the Yogyakarta sign language variety, MA dissertation. La Trobe University, Melbourne.

Sutton-Spence, Rachel. 1994. The role of the manual alphabet and fingerspelling in British Sign Language. PhD dissertation. University of Bristol, UK.

Wijaya, Laura Lesmana and Iwan Satryawan. 2013. Jakarta Sign Language Dictionary. Jakarta: University of Indonesia Press.

Woodward, James. 1989. Basic color term lexicalization across sign languages. Sign Language Studies, 63 (Summer) 145-152.

Zoetmulder, Petrus Josephus. 1982. Old Javanese-English Dictionary, The Hague: Martinus Nijhoff. In collaboration with Stuart Robson. 
